\title{
The Importance of Incorporating Local Culture into Community Development ${ }^{1}$
}

\section{A. Brennan²}

This paper is part of a series of discussions on community development. This series includes specialized papers on civic engagement, community action, and other topics important to the development of community.

\section{Introduction}

Developmental trajectories of communities are usually explained by reference to economic history, human capital deficits, and/or the structure of local labor markets. Rarely is local culture seen as playing a significant role in development outcomes. Nor does empirical research routinely consider the role of local culture in fostering a more complete understanding of community development. Instead, culture is often viewed as an outgrowth of a particular region and dependent upon economic and other experiences, not an independent force.

Such perspectives miss an important aspect of the development process. The culture of a community significantly shapes debate and action. Local culture also presents unique options for locally based economic and other development. Local understandings and interpretations of a community's history reflect past events that feed into, and are partially driven by the demands, sentiments, and interests of those in the present. This makes it crucial for community development practitioners to consider the importance of culture in efforts to improve local well-being. By paying attention to, and incorporating unique cultural values, traditions, and related factors, more efficient and effective development efforts can be achieved.

Local culture provides a sense of identity for rural communities and residents. This identity facilitates common understandings, traditions, and values, all central to the identification of plans of action to improve well-being. Culture contributes to building a sense of local identity and solidarity. It influences the confidence rural communities have for coming together to address specific needs and problems. This local commitment among residents, regardless of economic or political conditions, can serve as a valuable tool in shaping the effectiveness of development options and local actions. Such commitment, based on culture and common identity, can be seen as a potentially important tool in sustaining local government, development, and social improvement efforts.

1. This document is FCS9232, one of a series of the Family Youth and Community Sciences Department, Florida Cooperative Extension Service, Institute of Food and Agricultural Sciences, University of Florida. Original publication date October 19, 2005. Visit the EDIS Web Site at http://edis.ifas.ufl.edu.

2. M.A. Brennan, Assistant Professor of Community Development, Department of Family, Youth and Community Sciences, Cooperative Extension Service, Institute of Food and Agricultural Sciences, University of Florida, Gainesville, FL, 32611.

The Institute of Food and Agricultural Sciences (IFAS) is an Equal Opportunity Institution authorized to provide research, educational information and other services only to individuals and institutions that function with non-discrimination with respect to race, creed, color, religion, age, disability, sex, sexual orientation, marital status, national origin, political opinions or affiliations. U.S. Department of Agriculture, Cooperative Extension Service, University of Florida, IFAS, Florida A. \& M. University Cooperative Extension Program, and Boards of County Commissioners Cooperating. Larry Arrington, Dean 
Providing a local linkage and cultural basis for development is important. People are likely to take part in and remain committed to development efforts to which they have a direct connection. Development efforts that consider or focus on culture provide a mechanism for linking local residents to the development process. Through such efforts, local residents can encourage development that preserves or promotes their culture. This is particularly important in development efforts that seek to elicit local participation, volunteerism, and community action. In understanding the place of culture in the development process, it is important to consider the social basis of culture, its relationship to interaction, and the types of development and local actions it can contribute to.

\section{Role of Local Culture}

The concept of culture has many definitions and interpretations. In social settings, it is often used broadly to represent entire ways of life. Included in such ways of life are rules, values, and expected behaviors. At its most basic level, culture can be seen as the shared products of a society. These products have a common meaning that accumulates over time and also reflect shared attachments among community members.

Culture can be seen as consisting of ideas, rules, and material dimensions. Ideas include such things as the values, knowledge, and experience held by a culture. Values are shared ideas and beliefs about what is morally right or wrong, or what is culturally desirable. Such values are abstract concepts and are often based in religion or culture in that they reflect ideals and visions of what society should be. Such values often shape expected behavior and rules. These rules are accepted ways of doing things and represent guidelines for how people should conduct themselves and how they should act towards others.

Values and rules are often taken for granted and assumed to reflect a common understanding. Both, however, have direct origins and developed in response to conflicts or needs. At the core of such values and norms is a process of interaction that led to their emergence and acceptance. This process shapes the actions of individuals and social systems within their communities. Culture provides belonging and an arena in which residents can make a difference. At the same time, culture contributes to exclusionary practices and has been seen as a drag on development efforts. Regardless, it is clear that culture plays a critical role in local community action.

\section{Applied Uses of Culture in Development}

The inclusion of culture into community and economic development models can take many shapes and forms. Culture can serve as the central focus. Included would be tourism and other efforts that focus largely on the promotion, preservation, or enhancement of local or regional cultures. Culture can also be a factor that needs to be addressed to determine its impact on new or existing development programs (resource management, environmental protection). In facing development, the programs that communities are willing to accept and embrace are likely to depend largely on cultural factors. It is therefore vital that problems and potential solutions be defined in a manner consistent with the local culture.

\section{Culture as a Focus of Development}

Regional or local culture can serve as a basis for development. Such efforts can serve to promote the local identity, regional languages, and minority cultures. Efforts can focus on preservation or promotion of a culture, but can also use culture to mobilize the local population. Examples of cultural preservation or efforts focusing solely on a culture are often seen in relation to tourism and conservation efforts. Included are renovation of villages (architectural rehabilitation, etc.), highlighting the architectural heritage of an area (restoring historic sites to serve as a focal point for tourists), cultural venues (local heritage centers, traditional cultural events), traditional craft and artistic skills (development of industry and employment based on the production of items which are symbolic of the local culture), and cultural based entertainment and cultural dissemination (organization of cultural activities, festivals, permanent exhibitions). Equally important is the environmental aspects of culture, 
where traditional uses of natural resources or events symbolize local cultural ties to environmental processes (solstice festivals, harvest festivals, agriculture progress days).

These efforts serve as a basis for development, but also serve to maintain cultural traditions and ways of life. Furthermore, such forms of development highlight the importance of rural cultures and identify their role in shaping wider society. Finally, through such development, community and cultural identities are reinforced and collective identities strengthened. Such interaction can lead to an improved state of community and social well-being.

\section{Culture and Territorial Development}

It is argued by some that development should focus clearly on specific sectors of the economy, while others argue that rural development should be more tailored to the unique cultural characteristics of rural areas and highlight their territorial elements. These sectoral approaches have been central to most "top-down" or government-led development. Sectoral programs have however received criticism. Such programs are often seen as being too broad in scope and application to account for the diversity and unique needs of rural areas.

In response to such conditions, a shift from sectoral to territorial rural development policy has been suggested. In such policies, social cohesion and comprehensive planning have been included.

Territorial approaches are best suited to meet the unique and complex conditions present in rural areas. The local culture is part of this later development model. As a result, increasing attention is being given to local level and "bottom-up" approaches which focus on culture, territory, local diversity, and the optimization of local resources. Territorial approaches seek to enhance the particular strengths of a rural locality by developing the potential of local resources such as individuals, businesses, and communities. Such perspectives tend to include a recognition of the total environment in which local rural development operates. Such methods attempt to address the interdependencies of people, the environment, and the communities within a locality. Enhancing or focusing on local culture serves this process.

\section{Conclusion and Implications for Extension Programming}

The perceptions of rural and urban areas, their economic bases, and means for their development will need to be more closely considered in future policy efforts. This is particularly true when considering the changing character of rural areas and the diversity of communities there. Local culture plays a central role in shaping community development, local character, and responses to needs. Continuing to ignore culture's critical role will constrain development efforts, rendering them little more than short-term solutions for endemic rural problems.

The relationship between culture and community development is vast. However, this important relationship is rarely accorded a significant role in the design of development efforts. Using an interactional approach to community development provides opportunities for incorporating insights into the role and place of culture. Further, it means conceptualizing development so as to highlight the importance of establishing and enhancing social relationships. Aligning such development with cultural promotion and preservation can serve as a tool for successful development. Moreover, focusing on the erosion of solidarity or culture would provide insight into the lack of progress or the presence of obstacles impeding existing development efforts.

Future decisions will need to be made about the types of development activities pursued. In this light, territorial perspectives that focus on local cultures and their attributes appear to provide a more comprehensive approach than those that focus on specialized economic sectors. Local culture is a fundamental component of community life which shapes the unique character, needs, and possibilities of individual rural areas. Indeed, it differentiates communities making one-size-fits-all policies and programs largely irrelevant.

Culture and attachment to it can be used as a motivating factor in opposing "anti-local development" activities such as extralocal development and exploitation. Using culture to motivate community members can serve as a tool for 
policy makers and others interested in encouraging development at the local level.

Culture can be seen as presenting both the means and ends of development. To a great extent, it is by emphasizing the wealth and diversity of their cultural heritage that rural areas will be able to develop those activities that enhance social and economic well being. Communities and rural development specialists will need to understand and learn to capitalize on the strengths of community solidarity and culture.

\section{References and Suggested Reading}

Bhattacharyya, J. 1995. "Solidarity and agency: Rethinking community development." Human Organization. 54(1):60-69

Luloff, A.E., and J. Bridger. 2003. Community Agency and Local Development. Pp. 203-213 in, Challenges for Rural America in the Twenty-First Century, edited by D. Brown and L. Swanson. University Park, PA: Pennsylvania State University Press.

Ramsay, M. 1996. Community, culture, and economic development. Albany, NY: State University of New York Press.

Brennan, M. A. 2005a. "The Importance of Local Community Action in Shaping Development." EDIS. Gainesville, FL: Cooperative Extension Service, Institute of Food and Agricultural Sciences, University of Florida. Publication number: FCS 9209.

Brennan, M. A. 2005b. "Empowering Your Community: Stage 3, Goal Setting and Strategy Development." EDIS. Gainesville, FL: Cooperative Extension Service, Institute of Food and Agricultural Sciences, University of Florida. Publication number: FCS 9213.

Brennan, M. A. and C. Regan. 2005. "Empowering Your Community: Stage 2, Organization of Sponsorship.” EDIS. Gainesville, FL: Cooperative Extension Service, Institute of Food and Agricultural Sciences, University of Florida. Publication number: FCS 9212.
Luloff, A.E., and J. Bridger. 2003. Community Agency and Local Development. Pp. 203-213 in, Challenges for Rural America in the Twenty-First Century, edited by D. Brown and L. Swanson. University Park, PA: Pennsylvania State University Press.

Marcus, J. and M.A. Brennan. 2005. "Empowering Your Community: Stage 1, Initiation." EDIS. Gainesville, FL: Cooperative Extension Service, Institute of Food and Agricultural Sciences, University of Florida. Publication number: FCS 9210.

Wilkinson, K.P. 1991. The community in rural America. New York, NY: Greenwood Press, 1991. 